\title{
A DIÁSPORA SÍRIA: DA INTERNACIONALIZAÇÃO DO CONFLITO INTERNO AO TRATAMENTO JURÍDICO DISPENSADO PELO ESTADO BRASILEIRO AOS MIGRANTES
}

\author{
Daniel Braga Nascimento \\ Universidade Federal do Rio Grande do Sul - UFRGS - Brasil \\ Willian Moraes Roberto \\ Universidade Federal do Rio Grande do Sul - UFRGS - Brasil
}

\section{Resumo}

O conflito sírio gerou, até julho de 2016, 4,8 milhões de deslocados em países vizinhos (Iraque, Egito, Jordânia, Líbano e Turquia) e 900 mil na Europa. Internamente, 6,6 milhões de pessoas encontram-se deslocadas. Conforme o Alto Comissariado das Nações Unidas para Refugiados (ACNUR), 3 em cada 4 sírios vive abaixo da linha da pobreza. A guerra na Síria completou em 2016, 5 anos, e não vê perspectiva de apaziguamento e reestabelecimento da paz. Diante da maior crise de refugiados do nosso tempo, este artigo propõe analisar, de um lado, a internacionalização do conflito sírio e os motivos que levaram a um crescimento no número de refugiados internacionais, bem como os problemas por esses enfrentados em sua região e no continente europeu; e, de outro lado, a posição do Brasil como baluarte de uma política mais aberta ao recebimento de refugiados, visto ser o primeiro país das Américas a adotar procedimento especial que agilizou a concessão de vistos aos sírios. Tal procedimento deu-se através da resolução normativa número 17 do CONARE (Comitê Nacional para Refugiados), de 20/09/2013, o qual confere o visto humanitário a solicitantes oriundos da República Árabe da Síria, com fundamento em razões humanitárias. A resolução vigorou pelo prazo de 2 (dois) anos, sendo renovada, por igual período, em 21/09/2015 (Resolução Normativa CONARE n 20). Assim, até 21/09/2017, tal resolução permanece em vigor. No desenvolvimento da presente análise, questiona-se a postura do Estado brasileiro e a efetividade de tal procedimento, analisando-se as diferenças entre o status de refugiado respaldado pelo Estatuto dos Refugiados (Lei 9.474/1997) e o visto por razões humanitárias, concedido aos indivíduos afetados pelo conflito da República Árabe da Síria.

Palavras-chave: Migrantes. Refúgio. Síria. Visto humanitário.

\section{Introdução}

A temática dos refugiados se tornou o grande tema de mobilidade humana atualmente, visto o fluxo de milhares de pessoas para outros países, que não o seu de origem, pelas mais diversas razões. Os países receptores dividem-se entre países abertos ao recepcionamento de refugiados e aqueles que erguem seus muros físicos e também jurídicos, usando do aparato da força policial. 
Não há como não referenciar que o contexto atual de globalização perfaz a análise de que mercadorias e bens circulam livremente por todo o globo, ao passo que pessoas se veem privadas de mover-se, enfrentando as diversas amarguras e violências que conflitos geram em seus territórios. A América Latina, com reputação internacional de acolhida e concessão de asilo, é vista como uma porta de entrada para diversos refugiados no contexto global atual.

Em específico, é correto afirmar que a guerra que vem ocorrendo na Síria transformou-se em uma catástrofe humanitária. O conflito, que já entra em seu sexto ano, produziu a mais grave crise em termos de refugiados desde a Segunda Guerra Mundial. Entretanto, a situação alcançou tal ponto devido à internacionalização do conflito sírio a partir da ingerência de diversos outros Estados na disputa que, inicialmente, era interna e na esteira da Primavera Árabe. Dessa forma, a despeito de muitos governos hoje procurarem se eximir da responsabilidade frente à questão dos refugiados advindos da Síria, essa guerra transformou-se em tamanha tragédia pois houve a atuação de interesses estrangeiros sobre o país.

Historicamente, o Brasil sempre foi receptivo à admissão de estrangeiros em seu território. Em alguns momentos, houve mais restrição à entrada, e em outros, menos restrições, mas jamais houve proibição absoluta do ingresso. Atualmente, o diploma infraconstitucional que regulamenta o tema é o Estatuto do Estrangeiro (Lei n ${ }^{\circ} 6.815$, de 19 de agosto de 1980) (MALHEIRO, 2015) O refúgio é um instrumento de viés humanitário que se constroi a partir de um alcance universal, estabelecido pelo direito internacional para a proteção de determinadas pessoas que sofrem um fundado temor de perseguição ou uma grave e generalizada violação de direitos.

Nesse sentido, o presente artigo, em um primeiro momento, procura demonstrar os motivos que levaram o conflito na Síria a tornar-se internacionalizado, apontando a influência de atores estrangeiros no país e sua lógica. Em seguida, em um segundo momento, procura-se demonstrar que o grande número de refugiados sírios, consequência dessa guerra, encontra dificuldades para migrar e se readaptar, sobretudo em relação aos destinos no Oriente Médio e na Europa - inclusive em países envolvidos na guerra síria. Por fim, diante da contextualização da origem desse incremento no número de refugiados, analisa-se o caso brasileiro e o tratamento jurídico dispensado pelo Estado em relação a esses migrantes, que escolheram o país como destino frente aos problemas que poderiam enfrentar nos Estados vizinhos da Síria ou no continente europeu. 


\section{A internacionalização da guerra na Síria e a questão dos refugiados}

A partir de 2011, o mundo árabe foi abalado por uma série de protestos populares em diversos países, que clamavam por maiores liberdades políticas e melhores condições socioeconômicas de vida. A Síria foi abarcada por movimentos dentro dessa lógica, que tiveram início em março de 2011. O governo do presidente Bashar al-Assad respondeu com violência contra os manifestantes, fazendo com que a saída de Assad passasse a ser demandada. O confronto escalonou com o passar do tempo, ao ponto em que a oposição síria tornou-se armada e uma guerra civil eclodia no país.

Entretanto, o agravamento desta crise esteve ligado a um processo de internacionalização do conflito, na medida em que outros países passaram a interferir na Síria, cada qual buscando interesses próprios. Dessa forma, mais do que uma disputa entre facções sírias, o embate entre o governo de Assad e os rebeldes armados transformou-se em uma disputa geopolítica no Oriente Médio onde disputas de diversos níveis se cruzam - para além do interno, há uma questão regional entre as potências locais, bem como a nível global ao envolver os Estados Unidose aliados europeus (CHUBIN, 2012; BANDEIRA, 2013).

Em termos regionais, a Síria detém uma posição estratégica importante. Desde a Revolução Iraniana, em 1979, o regime sírio aproximou-se da República Islâmica e tornou-se a grande aliada árabe do Irã no Oriente Médio. De fato, através da Síria consolidou-se uma rede de contato entre o Irã e outros grupos não estatais, como o Hezbollah libanês e o Hamas palestino, que passaram a receber apoio material sírio e iraniano devido a uma convergência política, grosso modo, entre todos esses atores. De acordo com Mohns e Bank (2012, p. 25, tradução nossa), todos compartilham de uma postura de "oposição à Israel, rejeição às políticas ocidentais (principalmente dos Estados Unidos) no Oriente Médio, e antagonismo em relação aos países árabes pró-Ocidente e a favor do status quo como Egito, Jordânia e Arábia Saudita". Assim, para o Irã, a Síria constitui-se como "um posto de operações avançadas, um buffer estratégico e uma forma de projetar poder e influência no Levante (CHUBIN, 2012, p. 30, tradução nossa).

Desse modo, essa rede de relações ao redor de Síria e Irã consolidou-se como um dos lados da polarização do Oriente Médio, sobretudo nos anos 2000, depois da queda do regime de Saddam Hussein no Iraque (MOHNS; BANK, 2012). Quando a guerra na Síria eclodiu, os rivais regionais da República Islâmica, principalmente a Arábia Saudita, perceberam uma oportunidade de, através da deposição do regime em Damasco, enfraquecer o campo político oposto regional (CHUBIN, 2012). O reino saudita, historicamente competindo com a 
República Islâmica do Irã pela influência regional, passou a adotar uma política externa mais ofensiva a partir de 2011, encabeçando a articulação de apoio encoberto, financeiro e militar, à oposição síria através da Turquia e da Jordânia (FRIEDMAN, 2011).

A Turquia, por sua vez, envolveu-se na guerra síria a partir de 2011 segundo outra lógica. Historicamente distante do Oriente Médio, o Estado turco passou a voltar-se para a região de maneira mais efetiva sob o governo AKP (Partido da Justiça e Desenvolvimento), liderado por Erdogan. Ao longo dos anos 2000, a Turquia passou por um boom de crescimento econômico, ao mesmo tempo em que era governada por um partido de raízes islâmicas em um aparato estatal secular (KINZER, 2008). No contexto da Primavera Árabe, o governo turco julgou que ganhos estratégicos poderiam advir caso a Turquia apoiasse os novos movimentos na região que tentavam subir ao poder, especialmente porque muitos tinham raízes islâmicas e, inicialmente, afirmavam um interesse em criar regimes mais democráticos. Acreditando que poderia servir de exemplo de emulação para uma nova "onda democrática" na região, o que garantiria um aumento de sua influência, a Turquia apoia a oposição à Assad e toma parte da estratégia saudita de canalização de recursos aos rebeldes sírios (ROBINS, 2013; BARKEY, 2016).

Ao nível global, os Estados Unidos antagonizavam o Irã desde 1979 e, nos últimos anos, encontravam-se em disputa com a República Islâmica em virtude do seu programa nuclear. Entretanto, o governo Obama, assumindo depois de anos de guerras no Oriente Médio, buscava evitar uma nova intervenção direta na região. Quando as revoltas árabes eclodiram em meio à uma diminuição da presença diplomática e militar estadunidense do Oriente Médio, Washington apoiou e incentivou que atores regionais aliados tomassem a frente no conflito sírio - como Turquia e Arábia Saudita. Dessa forma, junto de aliados europeus membros da OTAN (Organização do Tratado do Atlântico Norte) que seguiam a mesma lógica, como França e Reino Unido, forneceu-se apoio diplomático e financeiro ao estabelecimento da rede regional de apoio à oposição síria, procurando formas não diretas de derrubar o regime de Assad e, através disso, enfraquecer o Irã e seu ímpeto confrontacionista com o Ocidente (GERGES, 2012; BANDEIRA, 2013).

Portanto, gradativamente a guerra síria transformou-se na manifestação de um conflito mais amplo entre dois campos políticos do Oriente Médio, onde o Irã e seus aliados protagonizavam um lado, e, de outro, cada qual por seus próprios motivos, encontram-se a Arábia Saudita e as petromonarquias do Golfo, com o apoio de Turquia, Estados Unidos e alguns aliados europeus (AYOOB, 2012; KHOURY, 2013). A Rússia também se colocou ao lado do regime de Assad, sobretudo a partir de 2013, devido às bases naval e aérea que possui 
nas cidades sírias de Tartus e Latakia, bem como por razões geopolíticas dado o acirramento dos problemas com o Ocidente após a crise ucraniana. Assim, percebe-se que houve grande ingerência externa sobre a Síria, com diversos países envolvidos no prolongamento da guerra e, consequentemente, na catástrofe humanitária por ele gerado.

A ascensão do grupo autodenominado Estado Islâmico (EI), responsável por perpetrar diversos atos terroristas, agravou ainda mais a situação política e também humanitária na Síria. Após terem decretado o novo califado com a tomada de Mosul, no Iraque, em junho de 2014, o EI avançou sobre diversos grupos étnicos que se negavam à conversão ou não aceitavam o domínio do grupo, tais como os Yazidis no Iraque e os curdos na Síria destacando, se por exemplo, a tentativa do EI de cercar a cidade de Kobani nos fins de 2014 (COCKBURN, 2015). É necessário destacar que a própria ascensão desse grupo somente foi possível com a desestabilização da Síria e, posteriormente, do Iraque, através da qual foi possível tomar territórios em um contexto de vácuo de autoridade e estatal e ampla disseminação de armas, munições e dinheiro nas mãos de outros grupos.

Dentro desse contexto, o conflito sírio já foi responsável por gerar, em termos humanitários, mais de 4,8 milhões refugiados e mais de 6,6 milhões de pessoas deslocadas internamente, até julho de 2016 (OCHA, 2016). Ou seja, de uma população estimada em 22 milhões, em 2011, mais de $20 \%$ fugiu do país e outros 30\% estão deslocados internamente portanto, metade da população de todo o país afetada somente em termos de mobilidade e de possuir um local adequado para residir.

A despeito do foco midiático recair sobre a entrada dos migrantes sírios para a Europa, são os países vizinhos à Síria, no Oriente Médio, o principal destino dessas pessoas. A Turquia é o país que mais recebeu sírios: 2,5 milhões de refugiados, até fevereiro desse ano (AI, 2016). O Líbano, por sua vez, recebeu 1,1 milhão, o que faz com que uma a cada cinco pessoas no país seja um sírio; já na Jordânia, há mais de 630 mil refugiados, o que equivale a $10 \%$ da população jordaniana (AI, 2016). Assim, mais de 4 milhões dos refugiados sírios encontram-se somente nesses três países.

A despeito dessa situação, muitos outros sírios preferem tentar a sorte em direção ao continente europeu, principalmente, devido aos problemas e dificuldades encontrados na vida nos campos de refugiados ou dada a instável situação política da região - os efeitos políticos e securitários da guerra na Síria já transbordaram para os países fronteiriços. Entretanto, a própria União Europeia (UE) vem passando por um momento de intensa crise, o que faz com que o fluxo de migrantes que chegam ao bloco seja visto como um fator desestabilizante para alguns dos países-membros. 
O bloco europeu ainda se recupera da crise econômica iniciada em 2008, que afetou em maior medida os países do sul da UE, como Portugal, Espanha e, principalmente, Grécia. Neste contexto de demorada recuperação e divergência entre os Estados-membros quanto aos rumos da economia do bloco, a UE sofre com uma escalada de ataques terroristas, com os perpetrados na França e Bélgica neste ano e no último (PORTER, 2016). Os fluxos de migrantes vindo para a Europa ocorrem neste cenário, o que faz com que membros do bloco europeu passem a securitizar a entrada de refugiados em seus territórios ao considerarem-nos um tipo de ameaça desestabilizante: seriam custos a uma economia já cambaleante e argumentos xenofóbicos e islamofóbicos de que em meio aos refugiados se daria a entrada de terroristas (PORTER, 2016). Essa visão se difunde pelo bloco graças ao aumento de força de partidos ultranacionalistas e de extrema direita, que não apenas são eurocéticos quanto ao bloco europeu como um todo, como também utilizam o argumento de ameaça frente aos refugiados.

Em 2015, especificamente, a Europa passou por um aumento do número de refugiados, principalmente entrando no continente pela Grécia. O número de chegadas pelo leste do Mediterrâneo saltou de 7,4 mil em outubro de 2014 para 171,5 mil em outubro de 2015 (STRATFOR, 2015). A rota dos migrantes passava pela Grécia e rumava ao norte, passando pela Macedônia, Sérvia, Croácia, Eslovênia, Áustria e Hungria. Dada o acirramento das visões políticas contrárias aos refugiados, cercas começaram a ser erguidas entre os Estados-membros, a despeito do acordo de livre circulação de pessoas da UE, e repressão policial foi amplamente utilizada contra os migrantes (STRATFOR, 2015). Destaca-se, por exemplo, a posição do governo húngaro, que se recusa a receber cotas de refugiados pelo bloco e ergueu cercas na fronteira com a Croácia em julho e outubro de 2015. É sintomático também desse processo as cercas erguidas pelos governos na Bulgária e Grécia nas fronteiras terrestres turcas (STRATFOR, 2015).

A própria Alemanha sofreu um abalo político interno frente ao tema. Nas eleições regionais de março de 2016, ocorridas em três das dezesseis regiões do país, resultou em um resultado recorde para o partido anti-imigração, Alternativa para Alemanha. O partido da União Democrática Cristã, base de Ângela Merkel, venceu em apenas uma delas, e com menos votos que no passado (STRATFOR, 2016). É nesse contexto que também se explica o acordo firmado no dia 18 de março entre Turquia e UE, através do qual o bloco expulsaria da Grécia imigrantes irregulares e os mandaria de volta à Turquia, a qual ficaria responsável por evitar que novos refugiados tentassem atravessar de maneira irregular o Mar Egeu (ABELLÁN, 2016). 
Portanto, os refugiados sírios não apenas tiveram de fugir de seu país devido à guerra na Síria, como depois passaram a enfrentar dificuldades nos principais destinos para onde migraram. Os países vizinhos no Oriente Médio já são os principais destinos dos sírios, mas passam por problemas políticos internos e sofrem com a instabilidade regional. A UE, por sua vez, adota uma postura cada vez mais fechada e anti-imigração como bloco, o que dificulta e dissuade os migrantes. Nesse cenário de acirramento das fronteiras e tensões, muitos sírios têm de buscar outros destinos, mais receptivos, para que possam reconstruir sua vida. É assim que o Brasil desponta como possibilidade - recebendo, até abril de 2016, mais de 2,2 mil sírios, $1 / 4$ do total de refugiados no país (REIS, 2016).

\section{Tratamento jurídico e visto humanitário}

Para analisar os instrumentos de proteção internacional mister se faz referir a relação entre o Direito Internacional dos Refugiados e o Direito Internacional dos Direitos Humanos. A proteção da pessoa se dá através de três vertentes do Direito Internacional: Direito Internacional dos Direitos Humanos, Direito Humanitário e o Direito Internacional dos Refugiados. Os três ramos, apesar de tratarem de temáticas específicas, se completem na sua proteção ao destinatário final (TRINDADE, 1996).

Das três vertentes, salutar destrinchar o Direito Internacional dos Refugiados a fim de buscar respostas a temática do presente artigo. Antes disso, não se pode dizer que tal proteção encontra-se deslocada dos Direitos Humanos, mas existe dentro dessa proteção. Não se pode pensar em Direito dos Refugiados, sem antes pensar que esses indivíduos possuem direitos pelo simples fato de serem humanos.

É na Declaração Universal dos Direitos Humanos que encontramos a primeira proteção referente ao asilo, conceito cunhado na Convenção de Genebra de 1951, sobre o Estatuto dos Refugiados e seu Protocolo de 1967. A ideia de que qualquer pessoa perseguida em seu país de origem pode solicitar asilo em outro para usufruir de proteção iniciou o reconhecimento de tal direito em diversos instrumentos, inclusive posteriores à Convenção. No contexto americano, cabe citar a importância da Declaração Americana dos Direitos Humanos, de 1948, em seu artigo 27 e a Convenção Americana de Direitos Humanos, de 1969, em seu artigo 22, promulgando, expressamente, o direito de buscar e receber asilo em razão de perseguição.

Os instrumentos citados se complementam entre si, no sistema universal, e no sistema regional, visando sempre a proteção da pessoa humana, sem distinção entre estrangeiros e 
nacionais. O princípio da não devolução é parte central do direito dos refugiados, o qual possibilita a proteção a todos os direitos referentes a pessoa humana. Por tal princípio, um solicitante de refúgio não pode ser devolvido para o país de origem, visto ser o local em que há um risco de ver violado seus direitos humanos, inclusive o direito à vida.

Na América Latina, o instrumento que tornou possível a concessão e expansão do conceito de refugiado foi a Declaração de Cartagena, de 1984. Já em 1994, a Declaração de São José sobre os refugiados e pessoas deslocadas aprimorou o conceito de refúgio, em especial ao deslocamento forçado. Refugiados, portanto, são aquelas pessoas que forçosamente, são obrigadas e saírem de seus países e buscarem proteção em outro, em razão de alguma perseguição. Cabe, assim, a comunidade internacional, buscar soluções para essas pessoas que necessitam de proteção.

Ainda sobre a especificidade de cada Estado, as hipóteses de concessão do status de refugiado são elencadas nos intrumentos internacionais que tratam da matéria e constituem padrões mínimos de proteção a serem adotados. Entretanto, a efetivação dessa proteção se dá no âmbito interno de cada Estado, os quais, por conseguinte, podem aumentar este rol de proteção, como no caso brasileiro, o qual adota a grave e generalizada violação de direitos humanos como justificativa para o reconhecimento do status de refugiado (JUBILUT, 2007, p. 43).

Através de todos os instrumentos internacionais de proteção, é possível referir o cumprimento das obrigações aceitas pelos Estados membros de tais acordos. Os Estados são soberanos para decidir sobre suas políticas migratórias, mas enfrentam um limite perante tais instrumentos internacionais. O controle de tais legislações se dá pela Corte Europeia de Direitos Humanos e a Corte Interamericana de Direitos Humanos, as quais ambas vêm decidindo no sentido de proteger os princípios que regem o Direito Internacional dos Refugiados, tais como o da não devolução e detenção arbitrária).

A proteção a qual se refere até o momento diz respeito a uma parcela do total de pessoas que se deslocam pelo globo. Em 2014, das 232 milhões de pessoas migrantes, estimase que 21,3 milhões eram solicitantes de refúgio ou refugiadas. Tendo em vista dos diversos fluxos migratórios atuais (profissional, estudantil, econômico, turístico) torna-se cada vez mais difícil a proteção daqueles que de fato sofrem alguma perseguição em seus Estados e por isso, deteriam uma maior proteção por parte do sistema internacional. A Convenção de Genebra, de 1951 foi ratificada por 143 Estados, inclusive o Brasil.

O conflito sírio viu desde o seu início a atuação de organizações humanitárias tentando responder às necessidades que o conflito gerou e ainda gera. $\mathrm{O}$ conflito sírio mostrou a 
necessidade de atuação conjunta de diversos países e soluções práticas de acolhimento dos fluxos de refugiados que surgiram. O sistema formal de proteção necessita desenvolver modos criativos de operar para efetivamente, atingir seus objetivos de proteção.

Nesse sentido, o CONARE (Cômite Nacional para Refugiados) - órgão colegiado, vinculado ao Ministério da Justiça, que reúne segmentos da área governamental, da sociedade civil e do ACNUR -, editou, em 20/09/2013, a Resolução Normativa $n^{\circ}$ 17. Tal resolução concede o visto humanitário a pessoas afetadas pelo conflito na República Árabe da Síria e vem possibilitar a emissão de vistos humanitários pela Embaixada Brasileira no Líbano, Jordânia e Turquia e demais missões diplomáticas. Em 20 de setembro de 2015, a resolução foi prorrogada para mais dois anos (Resolução n²0, de 20/09/2015). Em termos números, conforme o CONARE, em abril de 2016, o Brasil possuía 2.298 refugiados sírios reconhecidos.

Tal resolução possibilitou a combinação com a Resolução número 20 do CONARE, a qual disciplina a reunião familiar. Por tal instituto, refugiados com a sua condição reconhecida pelo Estado Brasileiro podem estender a proteção dada pelo visto humanitário, a seus familiares - em conformidade com o artigo 226 da Constituição Federal de 1988.

\section{Conclusões}

A Resolução Normativa $n^{\circ} 17$, prorrogada através da Resolução $n^{\circ} 20$, foi salutar na agilização do processo de concessão de visto para pessoas afetadas pelo conflito sírio. É de se reconhecer que tal ação conseguiu acelerar o processo de proteção internacional, visto possibilitar a solicitação ainda em países próximos da Síria.

No contanto, não há como não expressar preocupação no que se refere a proteção internacional, visto tal resolução não possuir a mesma segurança jurídica que a Convenção de Genebra de 1951. Uma resolução elaborada por um órgão do Poder Executivo, não possui a mesma força que uma Convenção ratificada internacionalmente pelo Brasil. Diz-se, portanto, que o refugiado sírio protegido pelo visto humanitário não possui o mesmo status de proteção que teria caso fosse reconhecido pela Convenção de 1951.

Apesar da necessária distinção entre os dois institutos, reconhece-se a efetividade, por hora, do visto por razões humanitárias. Percebe-se, porém, uma real necessidade de implementação de políticas públicas a agilizar o procedimento de concessão de visto e a necessária parceria entre os diversos órgãos de proteção. 


\title{
THE SYRIAN DIASPORA: FROM THE CONFLICT'S INTERNATIONALIZATION TO THE INTERNAL LEGAL TREATMENT GIVEN BY THE BRAZILIAN STATE TO MIGRANTS
}

\begin{abstract}
The Syrian conflict has generated, until July 2016, 4.8 million displaced people in neighboring countries (Iraq, Egypt, Jordan, Lebanon and Turkey) and 900,000 in Europe. Internally, 6.6 million people are displaced. According to the High Commissioner of the United Nations for Refugees (UNHCR), 3 out of 4 Syrians live below the poverty line. The war in Syria completed in 2016, five years, and don't see the perspective of reestablishment of peace. Facing the greatest crisis of our time refugees, this article aims to analyze, on the one hand, the internationalization of the Syrian conflict and the reasons that led to an increase in the number of international refugees and the problems those faced in the region and the European continent; and on the other hand, Brazil's position as a bulwark of a more open policy on receiving refugees, as it is the first country in the Americas to adopt special procedures that facilitated the granting of visas to Syrians. This procedure was made through the normative resolution number 17 of CONARE (National Committee for Refugees) of 09.20.2013, which provides humanitarian visa to applicants coming from the Syrian Arab Republic, based on humanitarian grounds. The resolution was launched for a period of two (2) years, and renewed for an equal period, on 21.09.2015 (Normative Resolution CONARE No. 20). So until 09/21/2017 such resolution remains in force. In the development of this analysis, it questions the position of the Brazilian state and the effectiveness of such a procedure, analyzing the differences between the refugee status supported by the Status of Refugees (Law 9.474 / 1997) and the visa on humanitarian grounds, granted individuals affected by the conflict of the Arab Republic of Syria.
\end{abstract}

Keywords: Migrants. Refuge. Syria. Humanitarian Visa .

\section{Referências}

ABELLÁN, Lucía. É assim que a Europa rejeita os refugiados sírios. El País, 23 de abril de 2016.2 Disponível em: <http://brasil.elpais.com/brasil/2016/04/22/internacional/1461359400_874893.html>.

AMNESTY INTERNATIONAL. Syria'srefugeecrisis in numbers. 3 de fevereiro de 2016. Disponível em: <https://www.amnesty.org/en/latest/news/2016/02/syrias-refugee-crisis-innumbers/>.

TRINDADE, Antônio Augusto Cançado, SANTIAGO, Gérard Peytrignet, Jaime Ruiz de. As três vertentes da proteção internacional dos direitos da pessoa humana: direitos humanos, direito humanitário, direito dos refugiados. Cômite Internacional da Cruz Vermelha. Alto Comissariado das Nações Unidas para os Refugiados, 1996.

AYOOB, Mohammed. The Arab Spring: Its GeostrategicSignificance. MiddleEastPolicy, v. XIX, n. 3, outono de 2012.

BANDEIRA, Luiz Alberto Moniz. A Segunda Guerra Fria: geopolítica e dimensão estratégica dos Estados Unidos. Rio de Janeiro: Civilização Brasileira, 2013. 
BARKEY, Henri J. Erdogan'sForeignPolicyIs in Ruins. ForeignPolicy, 4 de fevereiro de 2016. Disponível em: .

CHUBIN, Shahram. Iran andtheArab Spring: AscendancyFrustrated. GulfResearch Center, setembro de 2012. Disponível em: <http://carnegieendowment.org/files/Iran_and_Arab_Spring_2873.pdf>.

COCKBURN, Patrick. The Rise of Islamic State: ISIS and the new Sunni revolution. Londres: Verso, 2015.

Constituição da Republica Federativa do Brasil de 1988. Disponível em: <http://www.planalto.gov.br/ccivil_03/Constituicao/Constituicao.htm> Acesso em: 15 julho 2016

Convenção Americana dos Direitos Humanos. Disponível em: <https://www.cidh.oas.org/basicos/portugues/c.convencao_americana.htm> Acesso em: 15 julho 2016

Dados sobre refúgio no Brasil. Disponível em: <http://www.acnur.org/portugues/recursos/estatisticas/dados-sobre-refugio-no-brasil/> Acesso em: 15 julho 2016

Declaração Americana dos Direitos Humanos. Disponível em: <https://www.cidh.oas.org/basicos/portugues/b.Declaracao_Americana.htm> Acesso em: 15 julho 2016

Declaração de Cartagena. Disponível em: <http://www.acnur.org/fileadmin/Documentos/BDL/2001/0008.pdf> Acesso em: 15 julho 2016

Declaração Universal dos Direitos Humanos. Disponível em: <http://www.ohchr.org/EN/UDHR/Documents/UDHR_Translations/por.pdf> Acesso em: 14 julho 2016.

FRIEDMAN, George. Syria, Iran andthe Balance of Power in theMiddleEast. Stratfor, 22 de novembro de 2011. Disponível em: <https://www.stratfor.com/weekly/20111121-syriairan-and-balance-power-middle-east>.

GERGES, Fawaz A. Obama andtheMiddleEast: theendofAmerica'smoment? Nova York: PalgraveMacmillan, 2012.

JUBILUT, Liliana. O Direito internacional dos refugiados e sua aplicação no ordenamento jurídico brasileiro. São Paulo: método, 2007.

KHOURY, Nabeel A. The ArabCold War Revisited: the Regional ImpactoftheArabUprising. MiddleEastPolicy, v. XX, n. 2, verão de 2013.

KINZER, Stephen. Crescentand Star: TurkeyBetweenTwo Worlds. Nova York: Farrar, Straus e Giroux, 2008.

MALHEIRO, Emerson. Manual de Direito Internacional Privado. $3^{\circ}$ edição. São Paulo: Atlas, 2015 
MOHNS, Erik; BANK, André. SyrianRevoltFallout: EndoftheResistanceAxis? MiddleEastPolicy, v. XIX, n. 3, outono de 2012.

OCHA (United Nations Office for theCoordinationofHumanitarianAffairs). SyrianArabRepublic. 2016. Disponível em: 〈http://www.unocha.org/syria〉.

PORTER, Henry. Terrorism, Migrants, andCripplingDebt: isthistheendofEurope? Vanity Fair, fevereiro de 2016. Disponível em: <http://www.vanityfair.com/news/2016/01/europeterrorism-migrants-debt-crisis>.

Refugiados sírios são 4,8 mi em países vizinhos e 900 mil na Europa, diz ONU. Disponível em: http://g1.globo.com/mundo/noticia/2016/03/refugiados-sirios-sao-48-mi-em-paises-vizinhos-e-900-mil-naeuropa-diz-onu.html Acesso em: 14 julho 2016.

Resolução Normativa CONARE No 17, de 20/09/2013 Disponível em: <https://www.legisweb.com.br/legislacao/?id=258708> Acesso em: 14 julho 2016.

Resolução Normativa $\mathrm{n}^{\mathrm{o}}$ 16, de 20 de setembro de 2013. Disponível em: <https://www.legisweb.com.br/legislacao/?id=303612> Acesso em: 15 julho 2016

REIS, Thiago. Sírios já representam 1/4 dos refugiados no Brasil. G1, 24 de abril de 2016. Disponível em: <http:/g1.globo.com/mundo/noticia/2016/04/sirios-ja-representam-14-dosrefugiados-no-brasil.html>.

ROBINS, Philip. Turkey's "doublegravity" predicament: theforeignpolicyof a newlyactivistpower. InternationalAffairs, v. 89, n. 2, 2013.

STRATFOR. The RefugeeCrisis Redefines GermanPolitics. Stratfor, 14 de março de 2016. Disponível em: <https://www.stratfor.com/analysis/refugee-crisis-redefines-germanpolitics?topics $=284>$.

WhyGermanyCannot Stop theFlowofMigrants. Stratfor, 29 de outubro de 2015. Disponível em: <https://www.stratfor.com/analysis/why-germany-cannot-stop-flowmigrants>.

\section{Sobre os autores:}

Daniel Braga Nascimento é Advogado do GAIRE (Grupo de Assessoria a Imigrantes e a Refugiados- UFRGS), Mestrando em Direito pela Universidade Federal do Rio Grande do Sul - UFRGS. Endereço Eletrônico: danbragan@ yahoo.com.br

Willian Moraes Roberto é Graduado em Relações Internacionais pela Universidade Federal do Rio Grande do Sul (UFRGS), Mestrando pelo Programa de Pós-Graduação em Relações Internacionais San Tiago Dantas (UNESP - UNICAMP - PUC-SP). Endereço Eletrônico: willianmroberto@gmail.com 